brings out the retrogression as well as progression of cartographic publications throughout the years. "The force of bad example," he points out, "is a characteristic in the lives of maps as of men."

Mr. Wroth follows his subject closely and, while he is telling a story, the reader is not allowed to forget that the author is also talking maps and charts. He uses references to maps in his footnotes, instead of the usual quotations from historical manuscripts, to document his statements. In fact, twentyeight of the forty-one "works most frequently cited in notes" appended to the text, are studies on cartography, and several others are borderline works leaning strongly toward the subject of maps. Also appended is a list of IO4 of the principal maps mentioned, arranged in chronological order, with notes in each case as to the location of the particular copy consulted.

Special mention should be made of the twenty-two folding plates bound in with the text which are reproductions, in most cases reduced in size, of some of the most unusual maps and charts referred to. Besides adding to the general usefulness of the text as a reference work, they present to the reader, in some cases for the first time, rare treasures which many persons may never be privileged to see in the original. Some of these documents have long since been lost or destroyed, but their influence on cartographic history is incontestable. The reproductions are something of an achievement in themselves, and the collotype process has produced a finished product which is both attractive and remarkably legible.

This publication, a few copies of which are available in book form, separately paginated and with an index, presents a subject and a body of literature which is all too unfamiliar to geographers and historians of the present day. And yet it is no more possible to understand the history of the ancient Pacific without recourse to maps and charts than it is to study intelligently the present war in that area without them.-Lloyd A. Brown, librarian, Peabody Institute of the City of Baltimore.

\title{
Anniversaries and Holidays
}

Anniversaries and Holidays; A Calendar of Days and How to Observe Them. Mary Emogene Hazeltine. Second edition, completely revised with the editorial assistance of Judith K. Sollenberger. American Library Association, 1944. 316p.

The announcement that an excellent and time-tested reference tool has been revised is always good news to the reference librarian. Acquaintance with the first edition of Miss Hazeltine's "calendar-bibliography" assured us of excellence in the revision. Our expectations have been more than fulfilled; the new volume deserves an enthusiastic reception.

The revised edition adds many new names and anniversaries, completely revises the bibliographies, and arranges its material more compactly. Three of the parts have been telescoped into one, leaving five divisions in the book instead of seven. Calendar dates and code numbers for entries in the bibliography sections are in heavier type and placed more conspicuously in the page heading, making the volume easier to use.

The "Calendar" reflects trends in recent history and politics by the addition of such new anniversaries as Pan American Day, Atlantic Charter Day, Pearl Harbor Day, and independence days for Latin American countries, and by the appropriate omission of, for example, Germany's Constitution Day of 1919. Many of the special weeks and days publicized and celebrated in America have been included: Book Week, Garden Week, Buddy Poppy Week, Race Relations Sunday, and many others. Inauguration Day has been changed to January 20 , with a note regarding changes of date in its history.

The new "Calendar" contains 1387 personal names, approximately five hundred more than in the first edition. The names are chosen to represent all fields of endeavor and the new ones are chiefly those of persons who have become prominent in recent years, such as Stephen Vincent Benét, George Washington Carver,. Winston Churchill, George Gershwin, Mahatma Gandhi, Thomas Masaryk, the Mayos, and Toscanini. Some less important names in the old edition have been omitted. A number of entry dates have been 
corrected as a result of new research, nationality has been added to personal names, and the exact date of death has been given for deceased persons. A few typographical errors have crept in, as in the entries for John D. Rockefeller, that in the calendar and index being under July 9 and that in the classified index under July 8.

As before the "Calendar" contains brief or long descriptive notes for all entries, references by code number to information about the person or event in composite books listed in Parts II and III, and very complete bibliographies of historical, literary, and entertainment materials for important holidays. References to individual biographies, periodical references, and portraits have been almost entirely omitted.

Bibliographies in Parts II and.III have been thoroughly revised, with new titles replacing more than half of the earlier references whose content is now obsolete or incomplete. Many of the annotations have been rewritten. Titles in the two sections are numbered consecutively, and juvenile books are indicated by $j$ or $j i$ and by notation of the school grades for which they are suitable.

"Books about Holidays" (Part II) is arranged by general subjects connected with holiday and anniversary observance. In "Books about Persons" (Part III) collective biographies are arranged alphabetically by author and subject. To the reviewer it seems confusing to find the general references scattered among the classified lists, since the typography does not show too clearly the lines of demarcation. As a bibliographical list, Part III would be easier to use if the general references had been placed in a group at the beginning.

The classified index is a very useful guide to names of important persons in various occupations or fields of interest, and of important inventions. References given are to the calendar dates with which entries are associated and thus indirectly to material in books. The classification includes fifty-nine categories and is therefore fairly minute; there are also cross references to related fields. A few omissions of persons whose names appear in the calendar have been noted; e.g., Ibsen's name does not occur in the list of Scandinavian authors, though he is included under "Dramatists." Several others are in both groups.

The general index forms an adequate key to the events and persons in the book. References are to calendar dates or to pages. Names of individual inventions are omitted and may be found only in the classified index under "Inventions." References to subdivisions in the classified index are not always included; for example, the only reference to chemists, physicists, and geologists, is under the general heading "Scientists." A few additional cross references are needed: from Twain to Clemens, from Raphael to Sanzio, from Loyola to Ignatius of Loyola. There is also a certain inconsistency in the use of Christian names in the index.

The few defects mentioned are minor ones, inevitable in any book of such broad scope, and do not detract measurably from the usefulness of the volume as a whole. One would look long to find a more satisfactory tool for use on holiday or anniversary questions, at least from the librarian's point of view. Not so storied as Chambers' Book of Days, more concise and comprehensive than Douglas' American Book of Days, less international than Spicers' Book of Festivals, more selective in calendar and lists than White's Conspectus of American Biography, less concerned with "firsts" than Kane's Famous First Facts and More First Facts, this is still the best general tool in its field.

For exhibitors, advertisers, radio broadcasters and script writers, and for teachers, clergymen, and clubs, this book is a godsend. For librarians, who need not only information about days and their associations but also a key to fuller descriptions and biographies in the volumes on their shelves, it is an indispensable tool. As a buying list for library holiday collections it is the most valuable bibliography available today. Most libraries will wish to keep both editions available, since some books on their shelves may not be analyzed in the new edition of Anniversaries and Holidays.

Reference librarians owe a debt of gratitude to Miss Hazeltine for bringing up to date this invaluable reference tool.-Ruth $M$. Erlandson, reference librarian, White Plains, N.Y., Public Library. 